\title{
Impaired function of regulatory T-cells in hypersensitivity pneumonitis
}

\author{
M. Girard, E. Israël-Assayag and Y. Cormier
}

ABSTRACT: Hypersensitivity pneumonitis (HP) is characterised by lung lymphocytosis. Most individuals exposed to HP antigens remain asymptomatic. The mechanisms involved in the impaired immune tolerance leading to HP are unclear. Normally, T-regulatory (Treg)-cells control the immune response. The aim of the present study was to determine whether Treg-cell suppressive function deficiency can explain the uncontrolled inflammation in HP.

Bronchoalveolar lavage (BAL) and blood samples were obtained from normal subjects, asymptomatic individuals and HP patients. BAL and blood Treg-cells were isolated. The ability of Treg-cells to suppress T-cell proliferation and the role of interleukin (IL)-17 was verified.

BAL and blood Treg-cells from normal subjects suppressed the proliferative response of activated T-cells by 47.1 and $42 \%$, respectively. BAL and blood Treg-cells from asymptomatic subjects had a slightly decreased activity and suppressed proliferation by 29.4 and $31.8 \%$, respectively. BAL and blood Treg-cells from HP patients were totally nonfunctional and unable to suppress proliferation. Low levels of IL-17 were detected in sera and BAL from both normal and asymptomatic individuals, whereas measurable levels were found in patients.

Treg-cells may be involved in antigen tolerance in asymptomatic subjects. Defective Treg-cell function, potentially caused by increased IL-17 production, could account for the exacerbated immune response characteristic of HP.

\section{KEYWORDS: Extrinsic allergic alveolitis, T-cell regulation}

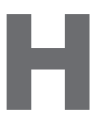

ypersensitivity pneumonitis (HP) is an inflammatory, granulomatous and immunologically mediated pulmonary disease caused by an exacerbated immune response to repeated inhalations of various antigens, which are mostly organic in nature. Animal and vegetable proteins, as well as bacteria, fungi and chemical compounds can cause HP [1]. For example, farmer's lung, one of the most common forms of $\mathrm{HP}$, is often caused by Saccharopolyspora rectivirgula actinomycetes found in poorly conserved hay, straw or grain [2].

$\mathrm{HP}$ is characterised by a large influx of activated lymphocytes in distal bronchioles and alveoli. Tcells can account for up to $60-80 \%$ of total bronchoalveolar lavage (BAL)-recovered cells from patients $[3,4]$. Chest radiography and computed tomography scans usually show diffuse ground-glass infiltrates and nodular and/or patchy air space opacifications [5]. In the chronic stage of the disease, some patients can develop emphysema and/or lung fibrosis [6].

Fortunately, very few individuals exposed to HP antigens develop these clinical symptoms. The prevalence of farmer's lung is estimated at $0.5-3 \%$ in exposed farmers $[7,8]$. Antigen-exposed persons often have specific serum antibodies and develop an asymptomatic lymphocytic alveolitis but seldom develop active disease [9]. They therefore seem to maintain a tolerance to the causative antigen.

Regulatory T-cells (Treg) are a unique population of CD4+ T-cells that play a pivotal role in the maintenance of the balance between the tissuedamaging and protective effects of the immune response. Treg-cells are generally defined by the extracellular expression of CD25, the high-affinity $\alpha$ chain of the interleukin (IL)-2 receptor (IL$2 \mathrm{R} \alpha$ ) [10], and by the intracellular expression of the forkhead/winged helix transcription factor (FoxP)3. To date, FoxP3 is the most specific marker for Treg-cells and the best method to distinguish them from other T-cells. In humans, purification can be enhanced by excluding T-cells that express CD127 and by including those that express CD39, CD73, LAG-3 (lymphocyte activation gene 3 ) and cytotoxic T-lymphocyte antigen (CTLA)-4, but none of these markers is exclusive to Treg-cells [11]. IL-17 is a pro-inflammatory cytokine induced mostly by T-helper (Th)17 cells, but also by natural killer cells, dendritic cells,
AFFILIATIONS

Centre de Recherche de I'Institut Universitaire de Cardiologie et de Pneumologie de Québec, Québec, $Q C$, Canada.

\section{CORRESPONDENCE}

Y. Cormier

Institut Universitaire de Cardiologie et de Pneumologie de Québec

2725 chemin Sainte-Foy

Québec

QC

G1V 4G5

Canada

E-mail: Yvon.Cormier@

med.ulaval.ca

Received:

April 092010

Accepted after revision:

June 302010

First published online:

July 222010 
CD8+ T-cells and $\gamma \delta$ T-cells. IL-17 promotes IL-1 $\beta$, IL-6 and IL-17 production by neighbouring cells, triggering a pro-inflammatory environment [12]. Secretion of pro-inflammatory cytokines, such as IL-1 $\beta$ and IL-6, can inhibit Treg-cell suppressive function $[13,14]$.

The aim of the present study was to verify the hypothesis that Treg-cells isolated from blood and BAL fluids of normal and asymptomatic subjects efficiently suppress Th-cell activation, while those from blood and BAL of patients suffering from active HP lose this suppressive function, allowing an exacerbated immune response and clinically significant lung inflammation. A secondary objective was to verify the potential role of IL-17, an inflammatory mediator known to affect Treg-cell function.

\section{MATERIALS AND METHODS}

The study population included: six male patients with active $\mathrm{HP}$, five subjects of whom farmer's lung and one of whom had $\mathrm{HP}$ to Paecilomyces sp. (mean age 48.5 yrs (range 31-69 yrs)); four asymptomatic, antigen-exposed (Paecilomyces sp.) male woodworkers, all of whom had high serum levels of immunoglobulin (Ig)G against the antigen (mean age 38 yrs (range 31-49 yrs)); and four unexposed control male subjects (mean age 39 yrs (range 30-45 yrs)). The diagnosis of HP was based on previously described criteria [15]. All patients were in the acute phase of the disease. The asymptomatic subjects had normal lung function and chest radiographs. As a group, the asymptomatic subjects were slightly younger than the subjects with HP. All subjects were nonsmokers, free of recent respiratory infections and taking no medication at the time of study. This project was approved by the Institut Universitaire de Cardiologie et de Pneumologie de Québec Research Center ethics committee (Quebec, QC, Canada) and all participants signed an approved consent form.

\section{Blood sampling and BAL}

All patients and volunteers underwent a $150 \mathrm{~mL}$ blood sampling and a fibre-optic bronchoscopy with BAL. The wedged lung segment was lavaged with five $60-\mathrm{mL}$ aliquots of normal sterile saline, pre-warmed to $37^{\circ} \mathrm{C}$; the fluid was gently aspirated after each aliquot. Lavage fluid was recovered and centrifuged, and the resulting BAL cells were counted in a haemocytometer. Differential cell counts were performed after Diff-Quik (Dade Diagnostics, Aguada, Puerto Rico) staining on glass coverslips.

\section{T-cell isolation from blood and BAL}

Blood and BAL mononuclear cells were isolated by Ficoll gradient centrifugation. Cells were plated for $2 \mathrm{~h}$ at $37^{\circ} \mathrm{C}$ in RPMI medium (GIBCO BRL, Burlington, ON, Canada) supplemented with $5 \%$ fetal bovine serum to separate monocytes (adherent) from lymphocytes (nonadherent cells). Lymphocytes were harvested from supernatants. Effector Tcells and Treg-cells were isolated using the $\mathrm{CD} 4^{+} \mathrm{CD} 25^{+}$ Regulatory $\mathrm{T}$ Cells Isolation Kit (Miltenyi Biotec, Auburn, CA, USA), and CD4, CD25 and FoxP3 expression was verified using phycoerythrin-Cy5-conjugated anti-CD4 and -CD25 monoclonal antibodies (BD Biosciences, Mississauga, $\mathrm{ON}$, Canada), and fluorescein isothiocyanate-conjugated antiFoxP3 monoclonal antibodies (eBioscience Inc., San Diego, CA, USA), respectively, in an EPICS XL-MCL flow cytometer
(Beckman-Coulter, Miami, FL, USA). The percentage of bloodand BAL-isolated CD4+ CD25+ Treg-cells among CD4+ T-cells were calculated for each group of subjects.

\section{In vitro suppression assays}

Isolated T-cells $\left(5 \times 10^{5}\right.$ cells $)$ were left unstimulated or stimulated with $10 \mu \mathrm{g} \cdot \mathrm{mL}^{-1}$ anti-CD3 and $4 \mu \mathrm{g} \cdot \mathrm{mL}^{-1}$ antiCD28 antibodies (both BD Biosciences) in 96-well, roundbottom plates. Equivalent numbers of Treg-cells from the same subject were added where appropriate. After a 4-day incubation, cells were pulsed with $1 \mu \mathrm{Ci}\left[{ }^{3} \mathrm{H}\right]$ thymidine per well for $16 \mathrm{~h}$ and proliferation was measured using a Packard Tri-Carb liquid scintillation counter 2100 TR (GMI Inc., Ramsey, MN, USA). Assays were performed in triplicate, or in duplicate when the number of Treg-cells was too small for a third assay (assays with BAL fluid cells from normal subjects). Data are presented as percentages of proliferation from control $\mathrm{T}$ effector cells exposed only to anti-CD3 and -CD28.

\section{Cytokine detection}

The concentration of IL-17A in sera and BAL, and the concentration of tumour necrosis factor (TNF)- $\alpha$ in BAL were measured in triplicate using ELISA kits (R\&D Systems, Minneapolis, MN, USA) according to the manufacturer's instructions.

\section{Statistical analysis}

Data are presented as mean $\pm \mathrm{SE}$ for graphical representation. For comparisons between group means, a one-way ANOVA was performed. We considered a p-value of $<0.05$ as a significant difference between groups.

\section{RESULTS}

\section{$B A L$}

Results of BAL total and differential cell counts are illustrated in figure 1a. Data are expressed in cells per millilitre of BAL. The exact number of cells that was recovered from the BAL of each group is presented in table 1 . Low cell counts were obtained for normal subjects. Asymptomatic subjects showed a moderate increase in total BAL cell counts and a slight increase of the percentage of lymphocytes (fig. 1b) compared to normal individuals. As expected, all BAL cell populations were increased in HP patients compared to other groups, with a marked increase in lymphocyte counts and percentages.

\section{CD4+ CD25- and CD4+ CD25+ T-cell isolation}

No significant difference was observed between healthy controls, asymptomatic subjects and HP patients with regard to the percentage of isolated CD4+ CD25+ cells of the total CD4+ T-cell populations from blood (fig. 2a) and BAL (fig. 2b). Isolated CD4+ CD25+ cells were mostly FoxP3+ and their frequency was comparable between groups of subjects. The expression of FoxP3 on isolated CD4+ CD25+ cells from blood and BAL was verified for each group and no statistical difference was observed between the groups (table 2). Table 2 also shows the mean fluorescence intensity of FoxP3, which was significantly different between normal subjects and HP patients for blood $(\mathrm{p}=0.0006)$ and BAL $(\mathrm{p}=0.0001)$. No significant difference was observed between asymptomatic individuals and the other groups. 

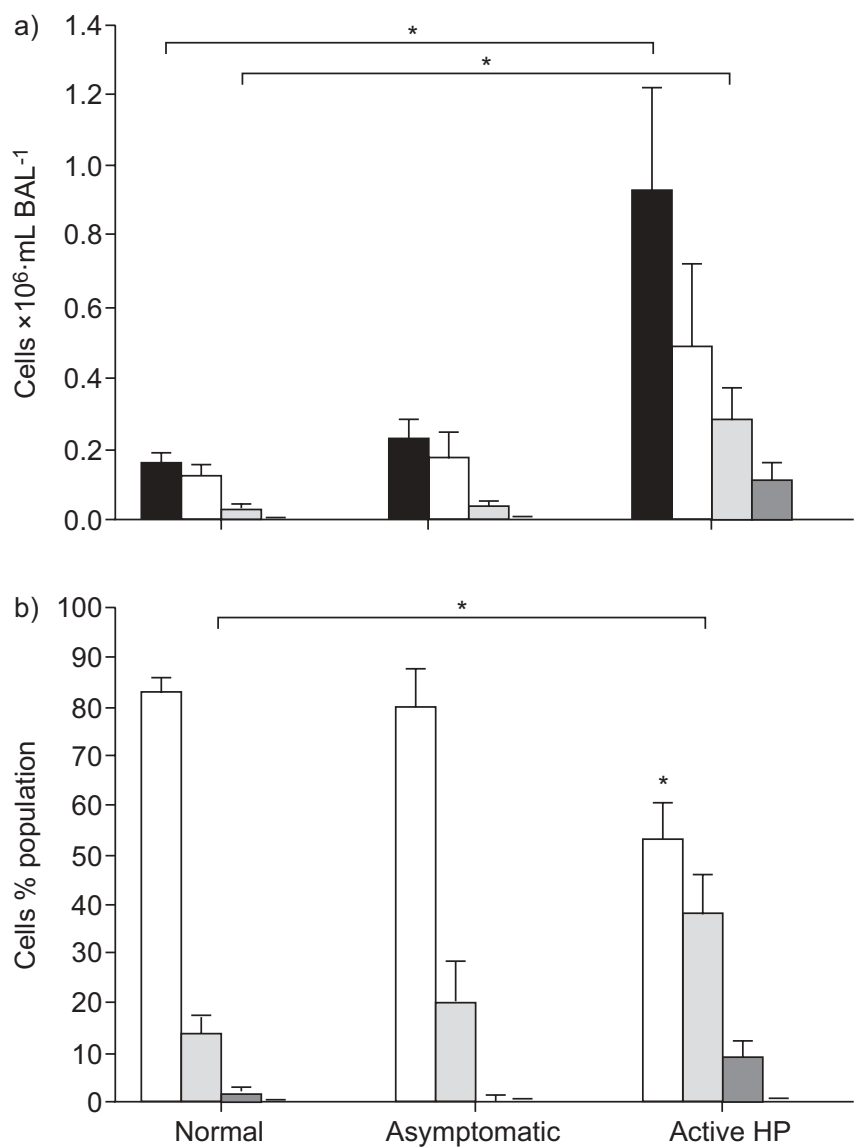

FIGURE 1. a) Total and differential bronchoalveolar lavage (BAL) cell counts from normal individuals, asymptomatic subjects and hypersensitivity pneumonitis (HP) patients expressed per millilitre of recovered BAL. Data are presented as mean \pm SEM. Inflammatory cells and lymphocyte counts of the HP patient group were significantly higher than control subjects: total cells $\left(0.928 \times 10^{6}\right.$ versus $\left.0.152 \times 10^{6} ; p=0.036\right)$; lymphocytes $\left(0.285 \times 10^{6}\right.$ versus $\left.0.021 \times 10^{6} ; p<0.018\right)$. b) Percentage of cell subpopulations recovered in BAL fluid from normal individuals, asymptomatic subjects and HP patients. Data are presented as mean \pm SEM. Percentage of lymphocytes from HP subjects is higher than those from normal individuals (37.9 versus $13.3 \% ; p=0.045$ ). There is an increase in lymphocyte percentage from asymptomatic subjects (20.17\%) but no significant difference from normal individuals $(p=0.45)$ or from HP patients $(p=0.21) . n=4-6$. : total cells; $\square$ : macrophages; $\square$ : Iymphocytes; $\mathbf{\square}$ : neutrophils; $\mathbf{m}$ : eosinophils.

\section{In vitro proliferation assays}

The results of in vitro proliferation assays are presented for blood (fig. 3a) and BAL cells (fig. 3b). Data are presented as a percentage of proliferation obtained from T-effector cells stimulated with anti-CD3 and -CD28 alone. Blood and BAL Treg-cells from normal individuals efficiently suppressed Teffector cell proliferation. When an equivalent number of Tregcells from normal individuals was added, proliferation of activated T-cells decreased to $58.0 \%$ of control proliferation for blood and $52.9 \%$ for BAL. BAL and blood Treg-cells from asymptomatic exposed subjects retained their ability to suppress T-cell proliferation. Proliferation of activated T-cells decreased to $70.63 \%$ of control proliferation for blood and $68.2 \%$ for BAL when Treg-cells were added to effector T cells. Treg-cells of HP patients from both blood and BAL were

\begin{tabular}{lccc}
\hline TALE 1 & $\begin{array}{l}\text { Cells recovered from bronchoalveolar lavage } \\
\text { (BAL) of normal individuals, asymptomatic } \\
\text { subjects and hypersensitivity pneumonitis (HP) } \\
\text { patients }\end{array}$ & & \\
& Normal & Asymptomatic & HP patients \\
\hline Subjects $\mathbf{n}$ & 4 & 4 & 6 \\
Total inflammatory cells $\times \mathbf{1 0}^{\mathbf{6}}$ & 29.82 & 35.63 & 134.57 \\
Macrophages $\times \mathbf{1 0}^{\mathbf{6}}$ & 24.72 & 28.58 & 72.13 \\
Lymphocytes $\times \mathbf{1 0}^{\mathbf{6}}$ & 3.97 & 7.20 & 51.00 \\
Treg cells $\times \mathbf{1 0}^{\mathbf{6}}$ & 0.12 & 0.17 & 2.81 \\
Neutrophils $\times \mathbf{1 0}^{\mathbf{6}}$ & 0.37 & 0.24 & 11.84 \\
Eosinophils $\times \mathbf{1 0}^{\mathbf{6}}$ & 0 & 0 & 0 \\
\hline Treg: T-regulatory. & & &
\end{tabular}

unable to suppress activated T-cell proliferation: $122.8 \%$ and $106.3 \%$, respectively.

\section{IL-17 and TNF- $\alpha$ analyses}

To study the mechanism by which the immune response could be exacerbated in HP, IL-17 was measured in the sera and BAL from the three study groups. No detectable levels of IL-17 were measured in the serum from normal individuals or asymptomatic subjects. Sera from patients with HP show a marked increase in IL-17 concentration (mean \pm SEM $210.47 \pm 95.24 \mathrm{pg} \cdot \mathrm{mL}^{-1}$; fig. 4a). No IL-17 was detected in BAL from normal individuals, whereas an intermediate amount was found in BAL from asymptomatic subjects $\left(192.37 \pm 83.45 \mathrm{pg} \cdot \mathrm{mL}^{-1}\right)$. An increased level of IL-17 was detected in BAL from $\mathrm{HP}$ patients $\left(580.07 \pm 138.68 \mathrm{pg} \cdot \mathrm{mL}^{-1}\right.$; fig. $4 \mathrm{~b})$. These results suggest that IL-17-secreting cells are activated in HP, and could be related to Treg-cell loss of suppressive function and enhanced influx of pro-inflammatory soluble factors and cells. In order to characterise the inflammatory response in HP patients and asymptomatic subjects, we also measured levels of TNF- $\alpha$ in BAL from each cohort (fig. 5). Normal subjects had small amounts of TNF- $\alpha$ in BAL $\left(210.83 \pm 46.26 \mathrm{pg} \cdot \mathrm{mL}^{-1}\right)$, whereas a slight increase is noted in BAL from asymptomatic individuals $\left(1,498.11 \pm 163.31 \mathrm{pg} \cdot \mathrm{mL}^{-1}\right)$. $\mathrm{HP}$ patients show a marked increase of this mediator in BAL $\left(3,233.78 \pm 282.51 \mathrm{pg} \cdot \mathrm{mL}^{-1}\right)$ compatible with a more intense inflammatory response.

\section{DISCUSSION}

Treg-cells are rare cells. Studying these cells in humans with a rare disease is a challenge. Characterisation of Treg-cells is less well defined in humans compared with mice, where definition of CD4+ CD25+ FoxP3+ cells as Treg-cells is well accepted. In humans, other markers, such as CD39, glucocorticoid-induced TNF receptor-related protein, CTLA-4, and the absence of CD127, is expected. However, due to very low number of isolated Treg-cells in BAL and blood, and the necessity of having a sufficient number of cells to carry out lymphosuppressive studies with confidence, the presence of all these markers could not be verified for this study. The fact that cells identified as CD4+ CD25+ FoxP3+ clearly showed lymphosuppressive properties suggests that these are indeed immuneregulatory cells. The message of this paper is not the precise 

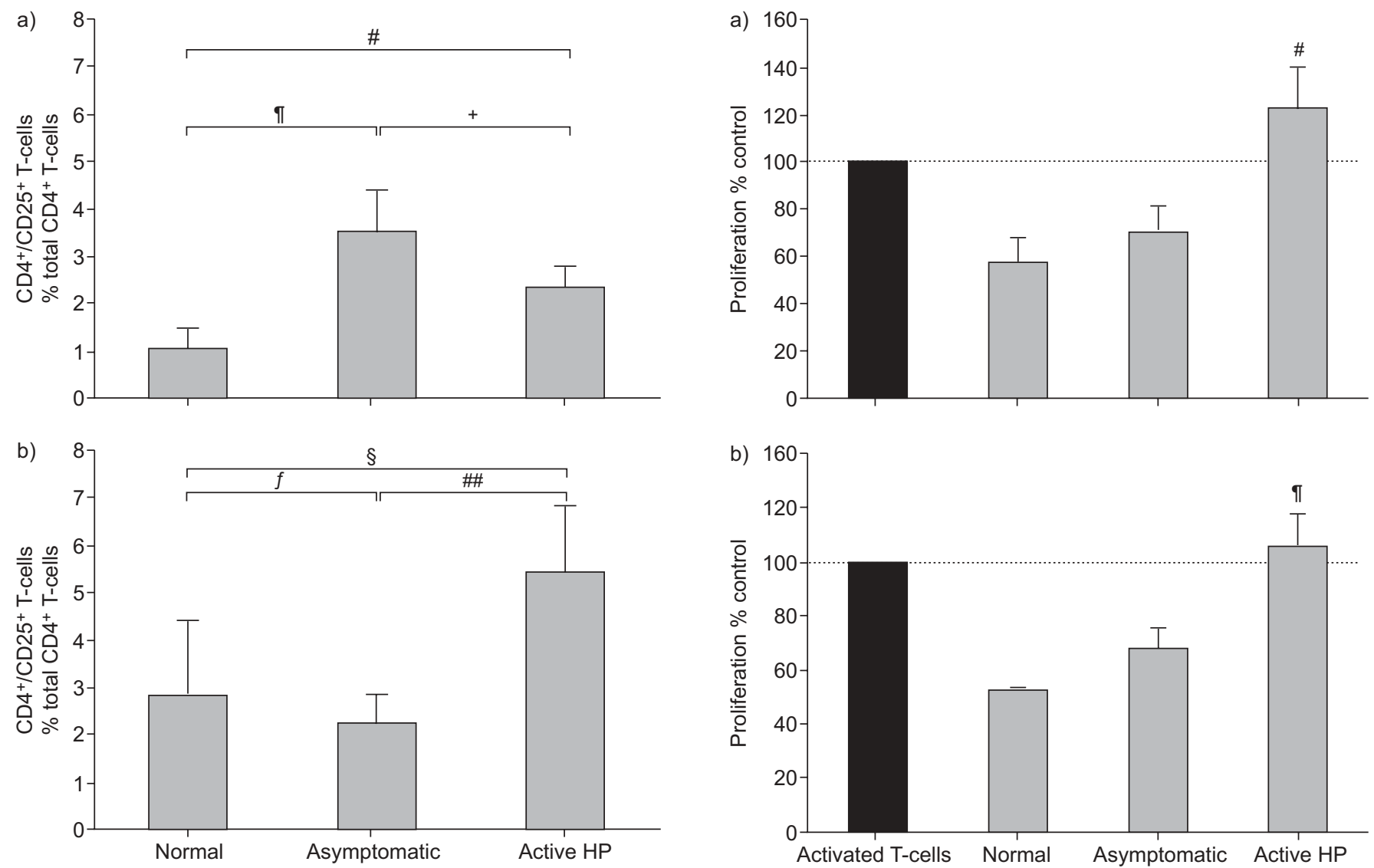

FIGURE 2. CD4+CD25+T-cells as percentages of the total CD4+ T-cells from a) blood and b) bronchoalveolar lavage for normal individuals, asymptomatic subjects and hypersensitivity pneumonitis (HP) patients. No significant differences were observed. Data are presented as mean \pm SEM. $n=4-6 .{ }^{\#}: p=0.14 ;{ }^{~}: p=0.062$; ${ }^{+}: p=0.21 ; \stackrel{s}{ }: p=0.25 ;$ f: $p=0.77 ; \# \#: p=0.16$.

identification of pure Treg-cells but that these cells have lost their normal lymphosuppressive function in acute HP.

Although the number of subjects per group was relatively small, which is understandable considering the orphan nature

FIGURE 3. T-regulatory (Treg)-cell function test studies. a) Blood and b) bronchoalveolar lavage (BAL) activated T-cells (anti-CD3/CD28) were placed in culture with an equivalent number of blood or BAL Treg-cells from normal individuals, asymptomatic subjects and hypersensitivity pneumonitis (HP) patients. Results are expressed as percentage of control activated T-cell proliferation. Data are presented as mean \pm SEM. Blood Treg-cells from normal $(58.0 \% ; p=0.02)$ and asymptomatic $(68.2 \% ; p=0.029)$ subjects efficiently suppressed $T$-cell proliferation compared to HP patients (122.83\%). BAL Treg-cells from normal $(52.88 \%$; $p=0.003)$ and asymptomatic $(70.6 \% ; p=0.025)$ subjects efficiently suppressed T-cell proliferation compared to HP patients (106.3\%). $n=4-6$. * $: p \leqslant 0.029$ ?: $p \leqslant 0.025$.

\section{TABLE 2 Percentage of FoxP3 expression and mean FoxP3 cell fluorescence intensity for normal individuals, asymptomatic} subjects and hypersensitivity pnuemonitis (HP) patients

FoxP3 expression \%

Mean fluorescence intensity $\mathrm{AU}$

\begin{tabular}{|c|c|c|}
\hline \multicolumn{3}{|l|}{ Normal } \\
\hline Blood & 92.9 & 45.3 \\
\hline $\mathrm{BAL}$ & 90.23 & 58.25 \\
\hline \multicolumn{3}{|c|}{ Asymptomatic } \\
\hline Blood & 88.75 & 15.88 \\
\hline BAL & 92.5 & 13.8 \\
\hline \multicolumn{3}{|c|}{ HP patients } \\
\hline Blood & 86.0 & 13.24 \\
\hline BAL & 88.3 & 7.99 \\
\hline
\end{tabular}

BAL: bronchoalveolar lavage; AU: arbitary units 

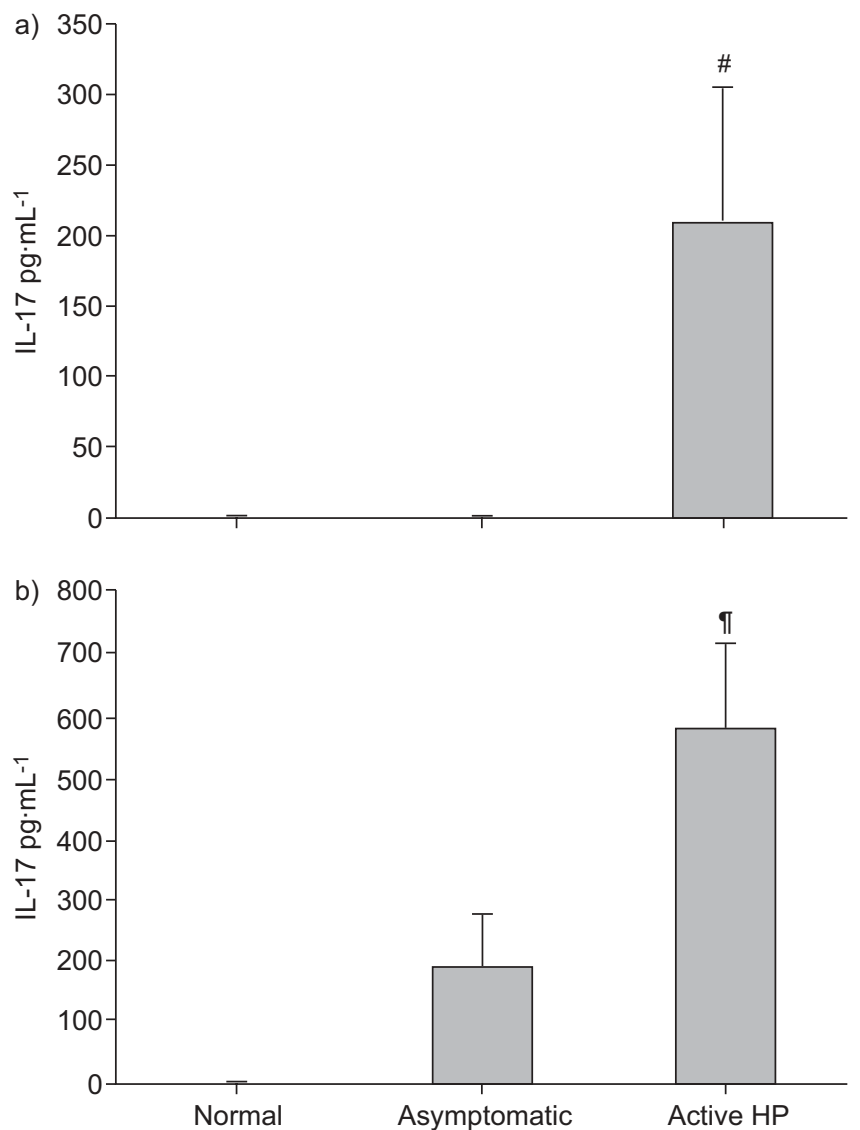

FIGURE 4. Concentration of interleukin (IL)-17 in a) serum and b) bronchoalveolar lavage (BAL) from normal individuals, asymptomatic subjects and hypersensitivity pneumonitis (HP) patients. Results are expressed as concentration $\left(\mathrm{pg} \cdot \mathrm{mL}^{-1}\right)$ of IL-17. Data are presented as mean \pm SEM. Little or no IL-17 was detected in the serum and BAL from healthy controls and asymptomatic individuals. A marked increase of IL-17 concentration was observed in serum of patients with HP $\left(210.47 \pm 95.24 \mathrm{pg} \cdot \mathrm{mL}^{-1} ; \quad \mathrm{p}=0.0369\right)$ and $\mathrm{BAL}\left(580.07 \pm 138.67 \mathrm{pg} \cdot \mathrm{mL}^{-1}\right.$; $p<0.017) . n=4-6 .{ }^{*}: p \leqslant 0.0369 ; ": p \leqslant 0.017$.

of the disease, the difference in Treg-cell function between patients with HP and the other two groups is striking and conclusive. Moreover, the fact that all proliferation assays and cytokine detection were performed in triplicate or in duplicate, depending on the number of Treg-celles, gives more accuracy to our data and confirms the reproducibility of the data.

The results of this study suggest that the immune response to HP-causing antigens is modulated by Treg-cell function. Although the percentage of Treg-cells among CD4+ T-cells was similar for the three groups, those from asymptomatic antigen-exposed individuals and from healthy control subjects efficiently suppressed the proliferation of effector T-cells, while those from HP patients had no suppressive activity. Moreover, even if the three groups had a similar percentage of FoxP3+ expression, fluorescence intensity of the FoxP3 marker was clearly decreased in HP patients compared with normal individuals, whereas cells from asymptomatic subjects showed an intermediate fluorescence. This dysfunctional phenotype of Treg-cells from HP patients could explain the large accumulation of lymphocytes in the lungs in these patients, while the

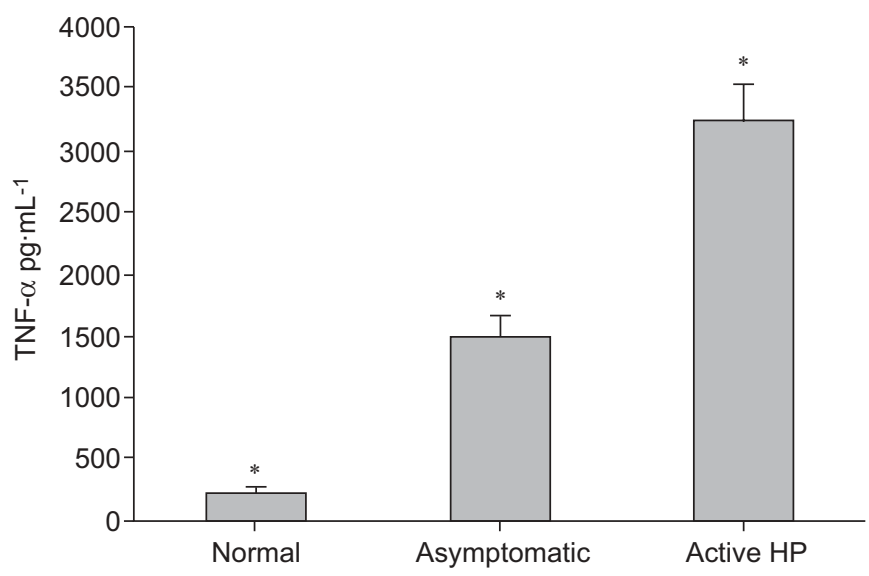

FIGURE 5. Concentration of tumour necrosis factor (TNF)- $\alpha$ in bronchoalveolar lavage (BAL) from normal individuals, asymptomatic subjects and hypersensitivity pnemonitis (HP) patients. Results are expressed as concentration $\left(\mathrm{pg} \cdot \mathrm{mL}^{-1}\right)$ of TNF- $\alpha$. Data are presented as mean \pm SEM. Small amounts were detected in BAL from healthy controls and intermediate levels were found in asymptomatic individuals. A marked increase of TNF- $\alpha$ concentrations were observed in the BAL of patients with $\mathrm{HP}\left(3,233.78 \pm 282.51 \mathrm{pg} \cdot \mathrm{mL}^{-1} ; \mathrm{p}<0.002\right)$. $n=4-6$. *: $p<0.05$

intermediate activity in asymptomatic subjects could be sufficient to control the disease.

These findings indicate that the normal Treg-cell lymphosuppressive function in asymptomatic subjects is able to attenuate the magnitude of the cellular immune response to inhaled antigens. The presence of significant levels of antigen-specific antibodies in the serum is indicative of an antigenic exposure. The suppression, although incomplete, since these subjects have a mild increase of lung inflammatory cells, may be sufficient to prevent the disease per se. The clinical significance of the lowgrade inflammation in asymptomatic subjects is supported by a follow-up study of dairy farmers who were presenting a slight increase in BAL lymphocytes, but remained asymptomatic and still had normal lung function after $20 \mathrm{yrs}$ [9].

Similarly to the low occurrence rate of HP and inherent mechanisms of immune tolerance to $S$. rectivirgula antigen in most exposed farmers, we have shown that in an S. rectivirgulainduced murine model of HP, the lymphocyte counts decrease with time and that Treg-cell suppressive functions appear after 10 weeks of repeated S. rectivirgula exposure (data not shown). Similar observations of attenuated inflammatory response were reported previously in mice exposed to $S$. rectivirgula antigen [16].

In the $S$. rectivirgula-induced murine model of $\mathrm{HP}$, the immune response seems to mimic the response of asymptomatic individuals. Other animal models studies have also shown that continued antigen challenge results in the waning of the pulmonary response rather than progression of the disease [17, 18]. These observations were also noted in humans where symptoms may be less severe with recurrent exposures [19].

Lung tolerance to a continuous exposure to antigens is well documented and has been attributed to a change in the phenotype of antigen-presenting dendritic cells. A decrease in major histocompatibility complex (MHC) class II and co-stimulatory 
molecules, and impairment of effector T-cell stimulation can lead to a tolerogenic dendritic cell phenotype producing IL-10 and/or transforming growth factor (TGF)- $\beta$, and induce a Treg-cell phenotype [20]. The low-grade continuous inflammation may be sufficient to induce the mechanisms of control of inflammation in asymptomatic exposed subjects.

In patients with $\mathrm{HP}$, the normal Treg-cell lymphosuppressive function is impaired; thus, lymphocytes are free to proliferate, accumulate in the lung and maintain an inflammatory environment. The events leading from the asymptomatic stage to the development of the disease that can explain this Tregcell loss of function are still unclear. As pointed out earlier, the prevalence of HP is very low and most subjects exposed to the causal antigens do not develop the disease. It has been suggested that some factors can trigger HP by breaking the homeostasis between immune tolerance and inflammatory mechanisms. Potential promoting factors for HP include a concomitant viral or bacterial infection, an increase in antigen load and a genetic predisposition. Patients suffering from acute bouts of $\mathrm{HP}$ often report initial symptoms suggestive of a respiratory viral infection. DAKHAMA et al. [21] reported the presence of viral antigens in the lungs of HP patients. We have previously reported that a viral infection could trigger an exacerbated immune response to $S$. rectivirgula antigen in a mouse model of HP [22]. In that viral-induced HP murine model, Sendai, a paramyxoviral infection, leads to dendritic cell maturation and upregulation of MHC class II and CD86 [23]. Indeed, some studies have shown that over expression of co-stimulatory molecules, such as MHC class II, CD80 and CD86, decreases the suppressive effects of Treg-cells and promotes effector T-cell activation [24]. Similarly, AHN et al. [25] reported that dendritic cells can reverse the suppressive effect of Treg-cells independent of cytokine production [25].

Defective Treg-cells have been reported in other inflammatory diseases, such as arthritis and multiple sclerosis [26, 27]. In a recent article, PARK et al. [28] demonstrated that Treg-cells are indeed implicated in S. rectivirgula-induced murine HP. Those authors showed an increased severity of HP in mice depleted

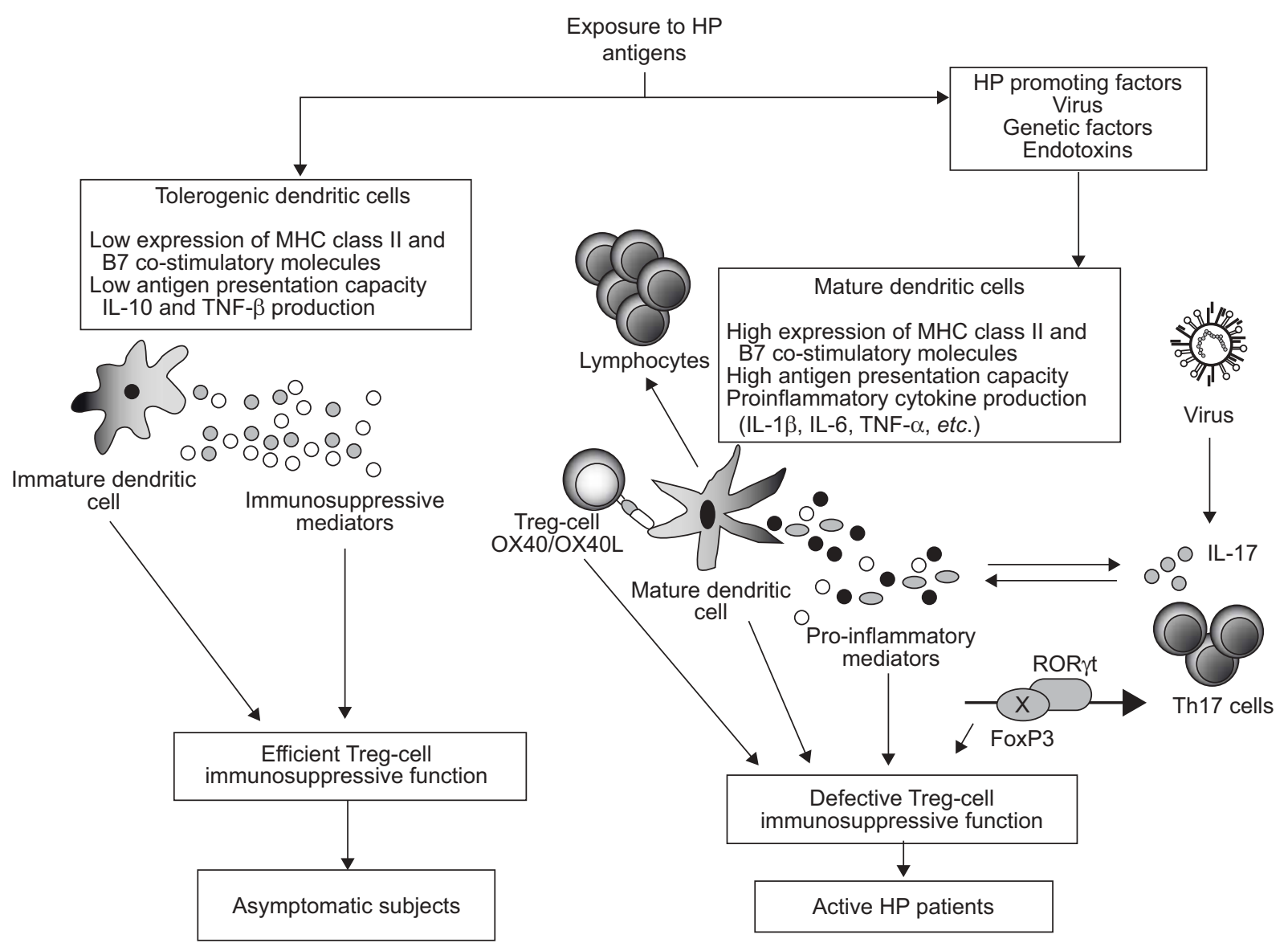

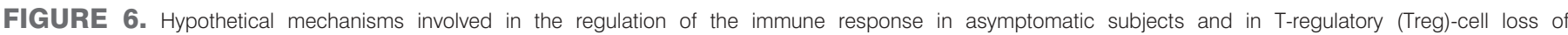

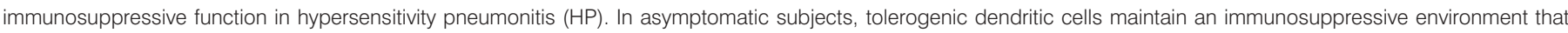

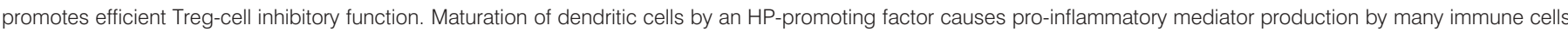

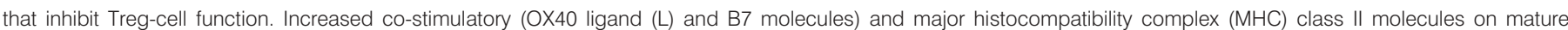

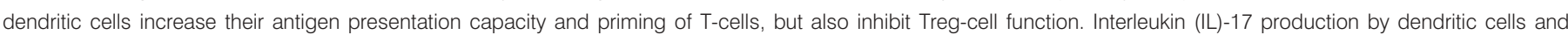

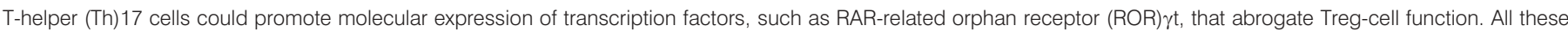

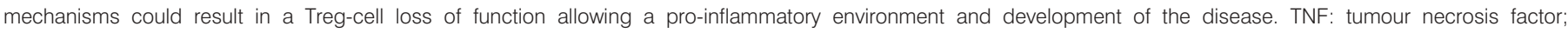
FoxP: forkhead/winged helix transcription factor. 
of CD25+ cells. These mice present a higher level of TGF- $\beta$ and interferon (IFN)- $\gamma$ in the lung, an increased number of inflammatory cells in BAL, more severe lung damage and a higher level of serum S. rectivirgula-specific IgG. An adoptive transfer of CD4+ CD25+ cells restores this inflammatory environment and decreases IFN- $\gamma$ production by $\mathrm{T}$-cells in the lung. These results demonstrate that CD4+ CD25+ cells play a protective role in $\mathrm{HP}$ by reducing IFN- $\gamma$ production by T-cells. However, in that study, no analysis of Treg-cell function was performed. The results of the present study demonstrate that in active human $\mathrm{HP}$, the regulation of the effector arm of the immune response is no longer under the control of Treg-cells. As a consequence, the exacerbated cellular influx and inflammatory mediators are most probably responsible for the acute phase of the disease. HP patients are not protected against inflammatory process because the CD4+ CD25+ cells have lost their suppressive function and can no longer control T-effector cell proliferation.

A recent explanation for the defective Treg-cell activity is that the presence of TNF- $\alpha$ impairs the suppressive function of Treg-cells [29]. Anti-TNF- $\alpha$ therapy is successful in restoring Treg-cell function in patients suffering from diabetes [26]. In the thymus, TNF- $\alpha$ could act on Treg-cells and cause the loss of their suppressive function. Recent observations suggest that Treg-cells are very sensitive to TNF- $\alpha$. Thymic CD4+ CD25+ cells derived from healthy donors show a higher expression of TNF receptor II than CD4+ CD25- cells [30]. Since TNF- $\alpha$ is increased in patients with HP (fig. 5) [31], it could potentially be a mechanism by which Treg-cells lose their immunosuppressive function in this disease.

The finding that IL-17 is increased in HP can also explain, in part, the impaired Treg-cell function as well as the exacerbation of the immune response characterising the disease. IL-17 is a pro-inflammatory cytokine produced mostly by Th17 cells. IL-17 promotes IL-6 and IL-1 $\beta$ production by neighbouring cells, triggering a pro-inflammatory environment [12]. These conditions, as well as interaction with pathogens, promote dendritic cell maturation and secretion of pro-inflammatory cytokines. Production of pro-inflammatory cytokines, particularly IL-6, IL- $1 \beta$ and TNF- $\alpha$, released by mature dendritic cells can subvert Treg-cell immunosuppressive function [13, 14]. Moreover, recent work demonstrated that, in the absence of a pro-inflammatory signal, FoxP3 can abrogate RAR-related orphan receptor (ROR) $\gamma \mathrm{t}$, a transcription factor for Th17 cells, and drive Treg-cell differentiation. In a pro-inflammatory environment, this inhibition is abrogated, IL-17-secreting Th17 cell differentiation is initiated and Treg-cell suppressive function is inhibited [32]. Moreover, in an inflammatory environment, Treg-cells can differentiate into Th17 cells and secrete IL-17 [33]. Th17 cells are involved in many autoimmune, inflammatory and infectious diseases [34-36]. A recent study reported the lung accumulation of CD4+ T-cells that produce IL-17 in HP patients [37]. Inflammatory mediators, such as TNF- $\alpha$ and IL-6, are involved in HP [38-40]. Recently, H1N1 influenza A virus infection has been found to promote an increase in pro-inflammatory mediators involved in the development of Th17 cells [41]. We hypothesise that an HP-promoting factor, such as a viral infection, could trigger the maturation of dendritic cells and the production of IL-17 by immune cells, contributing to the attenuation of Treg-cell suppressive function.

Another study by ITO et al. [42] indicates that maturation of dendritic cells stimulated by Sendai virus leads to an upregulation of co-stimulatory OX40 ligand (L) expression levels. Since Treg-cells express high levels of OX40, a member of TNF receptor family [43], and that binding of OX40 with its ligand on mature dendritic cells blocks Treg-cell suppressive function [44, 45], one might expect that such a mechanism would also affect the regulatory function of Treg-cells. Ligation of OX40 to its ligand does not affect the expression of FoxP3 in Treg-cells [43]. The molecular explanation for this Treg-cell loss of function is still unknown. Moreover, OX40-OX40L binding promotes $\mathrm{T}$-cell proliferation and increases the production of several cytokines [44]. Hence, in HP, mature dendritic cells could potentially inhibit Treg-cell function through OX40-OX40L binding. However, mature dendritic cells could promote the inflammatory environment by activating T-effector cells that trigger the lymphocytosis.

Similarly to other inflammatory and autoimmune diseases, a defect in Treg-cell function is involved in the pathology of HP. The events leading to the breakdown of the maintenance of the immune homeostasis to HP antigens needs to be further clarified. However, we hypothetise that impaired Treg-cell function is probably caused by multiple interdependent immune events (fig. 6). Maturation of dendritic cells by a cofactor, such as a viral infection, promotes a proinflammatory milieu that can, in turn, abrogate Treg-cell function in a cytokine-dependent or -independent way.

\section{SUPPORT STATEMENT}

The study was funded by Canadian Institutes of Health Research (CIHR).

\section{STATEMENT OF INTEREST}

None declared.

\section{REFERENCES}

1 Cormier Y, Israel-Assayag E. Pathogenesis of hypersensitivity pneumonitis. In: Wardlaw AJ, Hamid QA, eds. Textbook of Respiratory Cell and Molecular Biology. 1st Edn. London, Martin Dunitz Ltd, 2002; pp. 147-158.

2 Pepys J, Jenkins PA, Festenstein GN, et al. Farmer's lung: Thermoactinomyces as a source of farmer's lung hay antigen. Lancet 1963; 2: 607-611.

3 Semenzato G, Chilosi M, Ossi E, et al. Bronchoalveolar lavage and lung histology. Am Rev Respis Dis 1985; 132: 400-404.

4 Welker L, Jorres RA, Costabel U, et al. Predictive value of BAL cell differentials in the diagnosis of interstitial lung diseases. Eur Respir J 2004; 24: 1000-1006.

5 Girard M, Lacasse Y, Cormier Y. Hypersensitivity pneumonitis. Allergy 2009; 64: 322-334.

6 Patel AM, Ryu JH, Reed CE. Hypersensitivity pneumonitis: current concepts and future questions. J Allergy Clin Immunol 2001; 108: 661-670.

7 Selman M. Hypersensitivity pneumonitis. In: Schwarz M, King Jr $\mathrm{T}$, eds. Interstitial Lung Disease. 3rd Edn. Hamilton, Decker Inc., 1998; pp. 393-422.

8 Cormier $\mathrm{Y}$, Laviolette $\mathrm{M}$. Alvéolite allergique extrinsèque [Hypersensitivity pneumonitis]. In: Encycl Méd Chir. Paris, Elsevier, 1996; p. 6-039-E-30. 
9 Cormier Y, Létourneau L, Racine G. Significance of precipitins and asymptomatic lymphocytic alveolitis: a 20-yr follow-up. Eur Respir J 2004; 23: 523-525.

10 Sakaguchi S, Sakaguchi N, Asano M, et al. Immunologic selftolerance maintained by activated T cells expressing IL-2 receptor $\alpha$-chains (CD25). Breakdown of a single mechanism of selftolerance causes various autoimmune diseases. J Immunol 1995; 155: 1151-1164.

11 Workman CJ, Szymczak-Workman AL, Collison LW, et al. The development and function of regulatory T cells. Cell Mol Life Sci 2009; 66: 2603-2622.

12 Chang SH, Dong C. IL-17F: regulation, signalling and function in inflammation. Cytokine 2009; 46: 7-11.

13 Pasare C, Medzhitov R. Toll pathways-dependent blockade of $\mathrm{CD} 4{ }^{+} \mathrm{CD} 25^{+} \mathrm{T}$ cell-mediated suppression by dendritic cells. Science 2009; 299: 1033-1036.

14 O'Sullivan BJ, Thomas HE, Pai S, et al. IL-1 $\beta$ breaks tolerance through expansion of $\mathrm{CD} 25^{+}$effector T cells. J Immunol 2006; 176: $7278-7287$.

15 Israel-Assayag E, Dakhama A, Lavigne S, et al. Expression of costimulatory molecules on alveolar macrophages in hypersensitivity pneumonitis. Am J Respir Crit Care Med 1999; 159: 1830-1834.

16 Denis M, Bisson D, Ghadirian E. Cellular and cytokine profiles in spontaneous regression phase of hypersensitivity pneumonitis. Exp Lung Res 1993; 19: 257-271.

17 Schuley MR, Kleinerman J, Pensky JR, et al. Pulmonary response to repeated exposure to Micropolyspora faeni. Am Rev Respir Dis 1983, 128: 1071-1076.

18 Richardson HB, Richards DW, Swanson PA, et al. Antigen-specific desensitization in a rabbit model of acute hypersensitivity pneumonitis. J Allergy Clin Immunol 1981; 68: 226-234.

19 Bourke S, Banham S, Carter R, et al. Longitudinal course of extrinsic allergic alveolitis in pigeon breeders. Thorax 1989; 44: 415-418.

20 Cottrez F, Groux H. Specialization in tolerance: innate CD $4^{+} \mathrm{CD} 25$ versus acquired TR1 and TH3 regulatory $\mathrm{T}$ cells. Transplantation 2004; 15: S12-S15.

21 Dakhama A, Hegele RG, Laflamme G, et al. Common respiratory viruses in lower airways of patients with acute hypersensitivity pneumonitis. Am J Respir Crit Care Med 1999; 159: 1316-1322.

22 Cormier Y, Tremblay GM, Fournier M, et al. Long-term viral enhancement of lung response to Saccharopolyspora rectivirgula. Am J Respir Crit Care Med 1994; 149: 490-494.

23 Girard M, Israël-Assayag E, Cormier Y. Mature CD11c ${ }^{+}$cells are enhanced in hypersensitivity pneumonitis. Eur Respir J 2009; 34: 749-756.

24 Boissier MC, Assier E, Biton J, et al. Regulatory T cells (Treg) in rheumatoid arthritis. Joint Bone Spine 2009; 76: 10-14.

25 Ahn J, Krishnadas DK, Agrawal B. Dendritic cells partially abrogate the regulatory activity of $\mathrm{CD} 4^{+} \mathrm{CD} 25^{+} \mathrm{T}$ cells present in the human peripheral blood. Intern Immunol 2007; 19: 227-237.

26 Ehrenstein MR, Evans JG, Singh A, et al. Compromised function of regulatory $\mathrm{T}$ cells in rheumatoid arthritis and reversal by anti-TNF therapy. J Exp Med 2004; 200: 277-285.

27 Viglietta V, Baecher-Allan C, Weiner HL, et al. Loss of functional suppression by $\mathrm{CD} 4{ }^{+} \mathrm{CD} 25^{+}$regulatory $\mathrm{T}$ cells in patients with multiple sclerosis. J Exp Med 2004; 199: 971-979.

28 Park Y, Oh SJ, Chung DH. CD4+CD25+ regulatory $\mathrm{T}$ cells attenuate hypersensitivity pneumonitis by suppressing IFN- $\gamma$ production by $\mathrm{CD}^{+}$and $\mathrm{CD}^{+} \mathrm{T}$ cells. J Leukoc Biol 2009; 86: 1427-1437.

$29 \mathrm{Wu} \mathrm{AJ}$, Hua $\mathrm{H}$, Munson $\mathrm{SH}$, et al. Tumor necrosis factor- $\alpha$ regulation of $\mathrm{CD}^{+} \mathrm{CD} 25^{+} \mathrm{T}$ cell levels in NOD mice. Proc Natl Acad Sci USA 2002; 99: 12287-12292.

30 Annunziato F, Cosmi L, Liotta F, et al. Phenotype, localization, and mechanism of suppression of $\mathrm{CD} 44^{+} \mathrm{CD} 25^{+}$human thymocytes. J Exp Med 2002; 196: 379-387.

31 Ye Q, Nakamura S, Sarria R, et al. Interleukin 12, interleukin 18 , and tumor necrosis factor alpha release by alveolar macrophages: acute and chronic hypersensitivity pneumonitis. Ann Allergy Asthma Immunol 2009; 102: 149-154.

32 Zhou L, Lopes JE, Chong MM, et al. TGF- $\beta$-induced Foxp3 inhibits $\mathrm{T}_{\mathrm{H}} 17$ cell differentiation by antogonizing ROR $\gamma \mathrm{t}$ function. Nature 2008; 453: 236-240.

33 Beriou G, Costantino CM, Ashley CW, et al. IL-17-producing human peripheral regulatory $\mathrm{T}$ cells retain suppressive function. Blood 2009; 113: 4240-4249.

34 Park $\mathrm{H}$, Li Z, Yang XO, et al. A dinstinct lineage of CD4 $\mathrm{T}$ cells regulates tissue inflammation by producing interleukin-17. Nat Immunol 2005; 6: 1133-1141.

35 Fuss IJ, Becker C, Yang Z, et al. Both IL-12p70 and IL-23 are synthetized during active Crohn's disease and are down-regulated by treatment with anti-IL-12p40 monoclonal antibody. Inflamm Bowel Dis 2006; 12: 9-15.

36 van de Veerdonk FL, Gresnigt MS, Kullberg BJ, et al. Th17 responses and host defense against microorganisms: an overview. BMB Rep 209, 42: 776-787.

37 Simonian PL, Roark CL, Born WK, et al. $\gamma \delta \mathrm{T}$ cells and Th17 cytokines in hypersensitivity pneumonitis and lung fibrosis. Transl Res 2009; 154: 222-227.

38 Schuyler M, Gott K, Cherne A. Mediators of hypersensitivity pneumonitis. J Lab Clin Med 2000; 136: 29-38.

39 Denis M, Cormier Y, Laviolette M. Murine hypersensitivity pneumonitis: a study of cellular infiltrates and cytokine production and its modulation by cyclosporin A. Am J Respir Cell Mol Biol 1992; 6: 68-74.

40 Jones KP, Reynolds SR, Capper SJ, et al. Measurement of interleukin-6 in bronchoalveolar lavage fluid by radioimmunoassay: differences between patients with interstitial lung disease and control subjects. Clin Exp Immunol 1991; 83: 30-34.

41 Bermejo-Martin JF, Ortiz de Lejarazu R, Pumarola T, et al. Th1 and Th17 hypercytokinemia as early host response signature in severe pandemic influenza. Crit Care 2010; 13: R201.

42 Ito $T$, Amakawa $\mathrm{R}$, Inaba $\mathrm{M}$, et al. Plasmacytoid dendritic cells regulate Th cell response through OX40 ligand and type I IFNs. I Immunol 2004; 172: 4253-4259.

43 Croft M, So T, Duan W, et al. The significance of OX40 and OX40L to T-cell biology and immune disease. Immunol Rev 2009; 229: 173-191.

44 Kitamura N, Murata S, Ceki $\mathrm{T}$, et al. OX40 costimulation can abrogate Foxp $^{+}$regulatory $\mathrm{T}$ cell-mediated suppression of antitumor immunity. Int J Cancer 2009; 125: 630-638.

45 Duan W, So T, Croft M. Antagonism of airway tolerance by endotoxin/lipopolysaccharide through promoting OX40L and suppressing antigen-specific Foxp $3^{+}$T regulatory cells. J Immunol 2008; 181: 8650-8659. 